\title{
Epidemiology and Course of Gastrointestinal Haemorrhage in North-east Scotland
}

\author{
SHIRLEY J. JOHNSTON, PETER F. JONES, JAMES KYLE, CHARLES D. NEEDHAM
}

British Medical fournal, 1973, 3, 655-660

\section{Summary}

A prospective study was made of 817 consecutive episodes of major gastrointestinal haemorrhage in patients admitted to hospital during 1967-8 from the defined population of North-East Scotland. The yearly admission rate was 116 per 100,000 population. Comparison of the data for city and country residents showed no appreciable differences. In the duodenal ulcer group there was an undue incidence of bleeding among foremen and skilled workers and among those who were unmarried or widowed.

Both the clinical history and the results of any previous barium meal examinations were unreliable guides to the source of the current haemorrhage. Prognosis was worse for patients who did not have a dyspeptic history and was better for those who had bled on a previous occasion. The simultaneous ingestion of alcohol and aspirin had an adverse effect on the occurrence of bleeding. Forty-seven per cent. of the patients had another major coincidental disease.

Mortality was $13.7 \%$ in the whole series and $8.6 \%$ in those with peptic ulcer (duodenal ulcer $7 \cdot 1 \%$, gastric ulcer $16.9 \%$ ). In $28 \%$ of the patients further haemorrhage occurred after admission to hospital and caused a $\mathbf{2 8 . 8} \%$ mortality. Seventy-four patients were already in hospital when they first bled and $44 \%$ of them died.

\section{Introduction}

Though reports on gastrointestinal haemorrhage are numerous few give information related to a defined population. This pros-

\footnotetext{
Gastroenterological Investigation Unit, Aberdeen Royal Infirmary, Aberdeen AB9 2ZB

SHIRLEY J. JOHNSTON, F.R.C.s., Research Registrar

PETER F. JONES, M.CHIR., F.R.C.S., Consultant Surgeon

JAMES KYLE, M.CH., F.R.C.s., Consultant Surgeon

CHARLES D. NEEDHAM, M.D., F.R.C.P., Consultant Physician
}

pective study in the north-east region of Scotland examines the occurrence and pattern of presentation of haematemesis and melaena among adults in what is geographically a relatively closed community.

\section{Subjects and Methods}

This survey covered the period 1 January 1967 to 31 December 1968. Of the population of 442,000 in north-east Scotland (General Register Office, 1964) about 350,000 were aged 12 years or more and so were eligible for admission to the adult wards of the Aberdeen hospitals, which receive all major emergencies from the region. Accuracy of data recorded was assured by a detailed form being completed by one of us (usually S.J.J.) during the patient's stay in hospital. Care was taken to include patients who died soon after admission, those whose other severe concomitant disease could have prevented documentation of the bleeding, and those treated privately. The clinical care of these patients was under the control of the individual physicians and surgeons concerned.

\section{DEFINITIONS}

Bleeding.-Haematemesis was diagnosed when there was a clear history of vomiting blood or when this happened in the ward. "Coffee-ground" vomiting alone was not accepted as haematemesis unless confirmed by the presence of blood in vomit or faeces. Melaena was defined as the passage of altered blood per rectum in quantity. When there was firm operative, endoscopic, radiological, or necropsy evidence of a specific lesion this was taken to be the "proved" source of the bleeding. Where a likely clinical diagnosis could not be supported by objective evidence the diagnosis was accepted but considered to be "not proved." In 41 patients the source of bleeding could not be identified.

Gastritis.-In 11 patients gastritis or gastric erosion was seen at operation or necropsy. Otherwise the term "gastritis" was applied when in the absence of any other cause of bleeding there was evidence of the ingestion of large quantities of a potential gastric irritant.

Hiatus hernia was known to be present in many patients but 
TABLE I-Diagnostic Groupings in the 817 Episodes of Bleeding

Group

Duodenal ulcer $(n=434)$

Gastric ulcer $(\mathbf{n}=77)$

Gastritis/erosions $(n=55)$

Hiatus hernia $(n=66)$

\section{Diagnosis}

Duodenal ulcer

Acute peptic ulcer

Stomal ulcer

Stress

Gastric ulcer

Gastritis + erosions

Hiatus hernia only
Gastric ulcer + duodenal ulcer

Hiatus hernia + oesophagitis

Oesophageal varices

Mallory-Weiss tear

Neoplasms :

Benign $\{$ Stomach

$\left\{\begin{array}{l}\text { Stomach } \\ \text { Large and smali bowel }\end{array}\right.$

Salignant $\left\{\begin{array}{l}\text { Oesophagus } \\ \text { Stomach }\end{array}\right.$

Large and small bowel

Bleeding disorders

Embolism, vessel rupture

Embolism, vessel

Diverticular disease of colo

Colitis

Trauma

General diseases (renai, cardiovascular, and C.N. $\ddot{\text { S. }}$.

Postoperative haemorrhage

Source unknown

was considered to be the source of bleeding only in the absence of another cause.

Oesophagitis was diagnosed when it had been clinically troublesome and had been classified as severe at oesophagoscopy.

\section{INVESTIGATIONS}

The patients were assessed by standard clinical methods. Most patients not requiring emergency surgery had a barium-meal examination during the first week in hospital. Oesophagoscopy was used when varices or another oesophageal lesion were suspected. An emergency fibreoptic gastroscopy service was not available during the period covered by this report.

For the purpose of analysis the causes of bleeding are divided into six main groups-duodenal ulcer, gastric ulcer (including 13 patients who also had a duodenal ulcer), gastritis and erosions, hiatus hernia, miscellaneous, and source unknown (see table I).

\section{Results}

The final diagnoses made in 817 episodes of bleeding are listed in table I. The degree of certainty of diagnosis is indicated in table II.

The 817 episodes of bleeding occurred in 795 patients, of whom 16 were admitted twice and three were admitted on three occasions during the two years. Seventy-four of the patients were already in hospital when they first bled. There were therefore 116 episodes of bleeding a year per 100,000 of the adult population, or 92 per 100,000 of the total population. Admissions for haematemesis and melaena accounted for $8.4 \%$ of all emergency admissions to adult medical wards.

The sex and age distribution of the patients is set out in table III. Altogether $8.7 \%$ of the patients were aged 80 years or more. The sex of the patients did not affect the mortality rate.

Social Class and Occupation.-Social class (General Register Office, 1956) and socioeconomic status (General Register Office, 1967) of the males in the only large homogeneous group
TABLE II-Degree of Certainty of Diagnosis

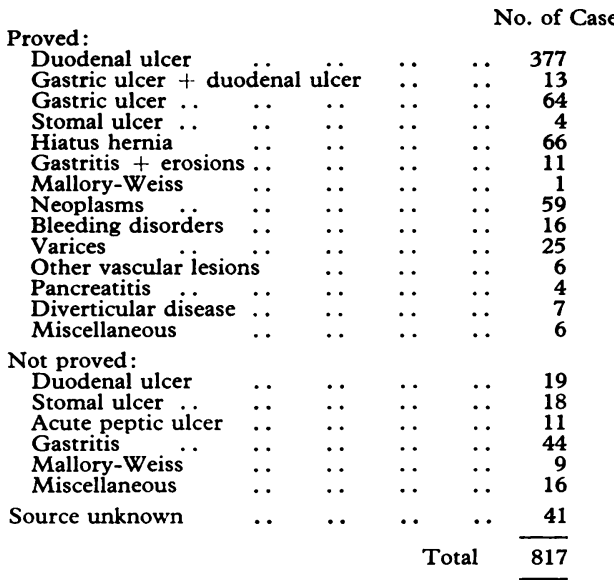

(duodenal ulcer) were compared with those of the adult population of north-east Scotland (General Register Office, 1964). There was a highly significant excess $(P<0.01)$ of patients in social class II and a significant excess $(P<0.05)$ among foremen and skilled workers (groups 8, 9, 12, 14) (General Register Office, 1967). Deviation from expected values did not reach significant levels in any of the other social classes or socioeconomic groups.

Marital Status.-In the duodenal ulcer group the number widowed was twice as great and the number never married one and a half times as great as in the population of North-east Scotland of similar age and sex (General Register Office, 1964). Differences were less marked when other lesions were the source of bleeding.

Place of Residence.-Aberdeen City and its immediate environs account for almost half the population of the North-Eastern Region and it produced just under half of the admissions to the survey. The small towns and country districts up to 70 miles $(113 \mathrm{~km})$ distant were responsible for admissions roughly in

TABLE III-Sex and Age Distribution. Figures are Percentages

\begin{tabular}{|c|c|c|c|c|c|c|c|c|c|}
\hline & & & Total & Duodenal Ulcer & Gastric Ulcer & Gastritis/Erosions & Hiatus Hernia & Miscellaneous & Source Unknown \\
\hline 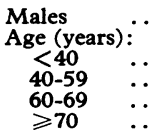 & $\begin{array}{l}. \\
. \\
\because \\
\because\end{array}$ & $\begin{array}{l}. . \\
\ldots \\
\because \\
.\end{array}$ & $\begin{array}{l}67 \cdot 9 \\
17 \cdot 2 \\
34 \cdot 0 \\
22 \cdot 2 \\
26 \cdot 6\end{array}$ & $\begin{array}{l}78 \cdot 0 \\
20 \cdot 7 \\
39 \cdot 9 \\
20 \cdot 5 \\
18 \cdot 9\end{array}$ & $\begin{array}{r}55 \cdot 8 \\
3.9 \\
38 \cdot 9 \\
28 \cdot 6 \\
28 \cdot 6\end{array}$ & $\begin{array}{l}65.5 \\
30.9 \\
30.9 \\
21.8 \\
16.4\end{array}$ & $\begin{array}{r}44 \cdot 0 \\
1 \cdot 5 \\
24 \cdot 2 \\
19 \cdot 8 \\
54 \cdot 5\end{array}$ & $\begin{array}{l}60 \cdot 0 \\
17 \cdot 4 \\
18 \cdot 1 \\
26 \cdot 4 \\
38 \cdot 1\end{array}$ & $\begin{array}{l}48 \cdot 8 \\
12 \cdot 2 \\
39 \cdot 0 \\
17 \cdot 3 \\
31 \cdot 5\end{array}$ \\
\hline
\end{tabular}


TABLE IV-Information obtained from History. Figures are Percentages

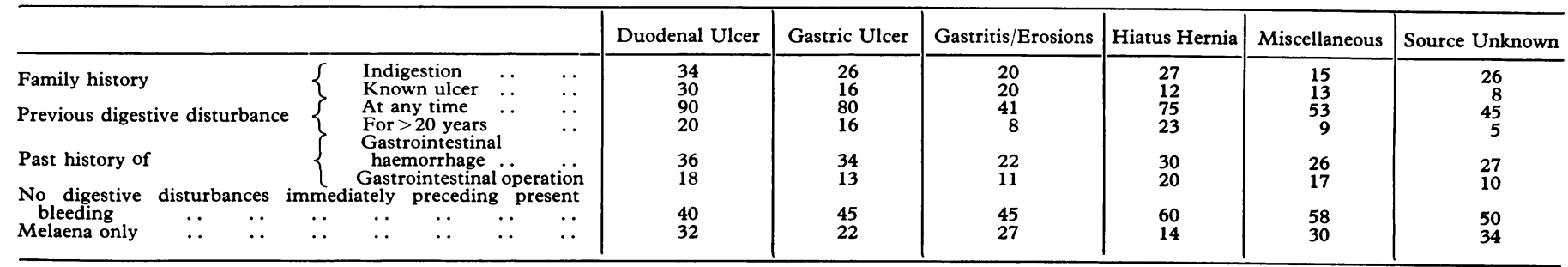

TABLE V-Findings on Previous Barium-meal Examinations. Figures are Percentages

\begin{tabular}{|c|c|c|c|c|c|c|c|}
\hline & & Duodenal Ulcer & Gastric Ulcer & Gastritis/Erosions & Hiatus Hernia & Miscellaneous & Source Unknown \\
\hline 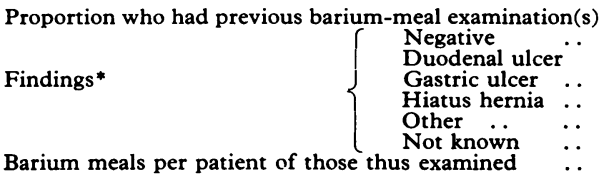 & $\begin{array}{l}\ldots \\
\cdots \\
\cdots \\
\cdots \\
\cdots\end{array}$ & $\begin{array}{r}51 \\
18 \\
67 \\
3 \\
4 \\
6 \\
5 \\
1 \cdot 44\end{array}$ & $\begin{array}{r}50 \\
22 \\
22 \\
42 \\
4 \\
4 \\
6 \\
1 \cdot 87\end{array}$ & $\begin{array}{l}20 \\
70 \\
12 \\
0 \\
24 \\
0 \\
6 \\
1 \cdot 54\end{array}$ & $\begin{array}{r}50 \\
5 \\
17 \\
0 \\
86 \\
3 \\
6 \\
1 \cdot 82\end{array}$ & $\begin{array}{r}31 \\
25 \\
25 \\
5 \\
24 \\
7 \\
14 \\
1.97\end{array}$ & $\begin{array}{l}27 \\
59 \\
18 \\
6 \\
0 \\
12 \\
6 \\
1.54\end{array}$ \\
\hline
\end{tabular}

*Includes multiple findings.

TABLE VI-Effect of History on Prognosis. Figures are Percentages

\begin{tabular}{l|c|c|c|c}
\hline & \multicolumn{2}{|c|}{$\begin{array}{c}\text { No Digestive Trouble } \\
\text { at Any Previous Time }\end{array}$} & $\begin{array}{c}\text { No Digestive Trouble } \\
\text { Immediately Preceding Bleeding }\end{array}$ \\
\cline { 2 - 4 } & $\begin{array}{c}\text { Those } \\
\text { Surviving }\end{array}$ & $\begin{array}{c}\text { Those } \\
\text { Dying }\end{array}$ & $\begin{array}{c}\text { Those } \\
\text { Surviving }\end{array}$ & $\begin{array}{c}\text { Those } \\
\text { Dying }\end{array}$ \\
\hline $\begin{array}{l}\text { Gastric ulcer } \\
\text { Duodenal ulcer }\end{array}$ & 21 & 23 & 45 & 61 \\
& 10 & 16 & 25 & 48 \\
\hline
\end{tabular}

proportion to their populations. City and country patients showed no significant differences in any of the data recorded including diagnostic pattern and mortality.

Time and Bleeding.- Seasonal variation was not marked but January was the busiest month, with some fall-off in midsummer. Monday was the busiest day, this being due entirely to the duodenal ulcer group. The reason for this was not obvious; there was no significant difference between the duodenal ulcer and other groups in terms of interval between onset of bleeding and admission. Sixty per cent. of all patients were admitted between 6 a.m. and 6 p.m., though the gastritis group reversed the diurnal pattern with only $44 \%$ being admitted during these times. Only $11 \%$ of all the patients were admitted between midnight and 6 a.m.

History. - The importance of a full history is emphasized repeatedly in the management of emergency admissions. The value of the history as a guide to the source of current haemorrhage was therefore carefully assessed. All aspects of the family and personal history were recorded in detail during the period of admission. The notes of nearly all previous admissions were available because these had usually been to the Aberdeen hospitals. Some of the results are given in tables IV and V, which show how little guidance is, in fact, obtained in the individual patient from either the history or the results of previous barium studies. The importance of the fact that prognosis is worse for the patient who does not have a dyspeptic history is emphasized in table VI. In each category a greater proportion of those dying than of those surviving denied previous dyspepsia. It made no difference whether the dyspepsia was felt immediately before the haemorrhage or at any previous time.

Drugs.-A large variety of drugs had been taken but some featured often enough to merit analysis. Ingestion of aspirin and alcohol was studied in some detail and was the subject of a separate report (Needham et al., 1971). For this study the aspirin or alcohol ingestion within 72 hours of the onset of bleeding in each of the six diagnostic groups was compared with (a) aspirin ingestion in a control group of 300 patients and $(b)$ alcohol ingestion in the 118 of that control group who were questioned on this point. Statistical analysis showed that there was a highly significant association between aspirin ingestion and bleeding. Though ingestion of alcohol alone before bleeding was not significant the combination of alcohol and aspirin produced an effect not only highly significant but also truly synergistic. Within the limits of our data we did not find any increased incidence of alcoholism in our patients as compared with the general population. Fourteen patients bled while receiving antirheumatic drugs. Ten patients, all with other serious diseases, bled while taking steroids. Fifteen patients bled while on anticoagulant treatment -13 on long-term oral therapy and two on heparin in the ward. At the time of the survey 475 patients were attending anticoagulant clinics in the region.

Coincidental Diseases.-Another disease completely unconnected with the cause of the bleeding was already present in 390 patients, and often more than one system was involved. The possible effect on mortality is examined in our accompanying paper (Jones et al., 1973).

Patients Already in Hospital.-Seventy-four patients were already in hospital when they first bled, and $44.6 \%$ of this group died; of the remaining 743 patients only $10.6 \%$ died. In $33 \%$ of the 74 patients haemorrhage occurred within 72 hours of admission for other disorders but in $54 \%$ it was delayed for more than a week. Though only 23 of the 74 patients had been admitted for an alimentary disorder the pattern of bleeding in all 74 was very similar to that found in the remaining 743; however, the mortality was much greater (table VII). Further haemorrhage after the initial episode occurred in 37 of the 74 patients, with a mortality of $51 \%$. The occurrence of further haemorrhage did not of itself account for this very high mortality because the other 37 patients not suffering this comlication had a mortality of $38 \%$. Other coincidental disease apart from the bleeding was necessarily present in all of the 74 patients compared with $42.5 \%$ of the other 743 . A further clear difference between the two groups was that $75 \%$ of the 74 patients were aged more than 60 years, as opposed to $43 \%$ of the 743.

Blood Groups.-The blood group distribution in the six diagnostic categories is shown in table VIII and compared with that found in 19,000 schoolchildren aged 5-17 years in northeast Scotland (Allan, 1971). The group $O$ preponderance is seen to be at the expense of group $A$.

Pattern of Bleeding.-Among the 817 episodes of haemorrhage, 
TABLE VII-Diagnosis and Mortality of Inpatients suffering their Initial Haemorrhage after Admission

\begin{tabular}{|c|c|c|c|c|c|c|c|c|}
\hline & & Total & Duodenal Ulcer & Gastric Ulcer & Gastritis & Hiatus Hernia & Miscellaneous & Source Unknown \\
\hline $\begin{array}{l}\text { No. already in hospital } \\
\text { No. }(\%) \text { who died }\end{array}$ & $\because$ & $\begin{array}{c}74 \\
33(44 \cdot 6)\end{array}$ & $10(40)$ & $\begin{array}{l}6 \\
3\end{array}$ & 2 & $\begin{array}{l}4 \\
0\end{array}$ & 1629 & $\begin{array}{c}8 \\
2(25)\end{array}$ \\
\hline $\begin{array}{l}\text { No. admitted because } \\
\text { haemorrhage } \\
\text { No. (\%) who died }\end{array}$ & $\begin{array}{l}\text { of } \\
\cdots \\
\cdots\end{array}$ & $\begin{array}{c}743 \\
79(10 \cdot 6) \\
\end{array}$ & $\begin{array}{r}409 \\
21(5 \cdot 1) \\
\end{array}$ & $\begin{array}{c}71 \\
10(14 \cdot 1) \\
\end{array}$ & $\begin{aligned} & 53 \\
& 5(9 \cdot 4) \\
&\end{aligned}$ & $\begin{array}{r}62 \\
2(3 \cdot 2) \\
\end{array}$ & $\begin{array}{l}115 \\
37(32) \\
\end{array}$ & $4 \stackrel{33}{(12)}$ \\
\hline $\begin{array}{l}\text { No. in whole series } \\
\text { No. }(\%) \text { who died }\end{array}$ & $\begin{array}{l}. \\
\cdots\end{array}$ & $\begin{array}{c}817 \\
112(13 \cdot 7)\end{array}$ & $\begin{array}{l}434 \\
31(7 \cdot 1)\end{array}$ & $\begin{array}{c}77 \\
13(16.9)\end{array}$ & $\begin{array}{l}55 \\
7(12 \cdot 7)\end{array}$ & 266 & $\begin{array}{c}144 \\
53(36 \cdot 8)\end{array}$ & $\begin{array}{c}41 \\
6(14 \cdot 6)\end{array}$ \\
\hline
\end{tabular}

TABLE viII-Blood Group Distribution. Figures are Percentages

\begin{tabular}{|c|c|c|c|c|c|c|c|}
\hline Blood Group & $\begin{array}{l}\text { Population } \\
\text { N.E. Scotland }\end{array}$ & Duodenal Ulcer & Gastric Ulcer & Gastritis/Erosions & Hiatus Hernia & Miscellaneous & Source Unknown \\
\hline $\begin{array}{r}\mathbf{O} \\
\mathbf{A} \\
\mathbf{B} \\
\mathbf{A B}\end{array}$ & $\begin{array}{r}49 \cdot 9 \\
36 \cdot 0 \\
10 \cdot 7 \\
3.3\end{array}$ & $\begin{array}{r}57 \cdot 7 \\
31 \cdot 3 \\
9.0 \\
1.9\end{array}$ & $\begin{array}{r}61 \cdot 3 \\
25 \cdot 4 \\
9 \cdot 3 \\
4 \cdot 0\end{array}$ & $\begin{array}{r}72 \cdot 7 \\
18 \cdot 2 \\
6 \cdot 8 \\
2 \cdot 3\end{array}$ & $\begin{array}{c}58.0 \\
29.0 \\
13.0 \\
0\end{array}$ & $\begin{array}{r}47 \cdot 3 \\
38 \cdot 1 \\
11 \cdot 5 \\
3 \cdot 1\end{array}$ & $\begin{array}{c}45 \cdot 7 \\
34 \cdot 3 \\
20 \cdot 0 \\
0\end{array}$ \\
\hline
\end{tabular}

TABLE IX-Severity of Bleeding. Figures are Percentages

\begin{tabular}{|c|c|c|c|c|c|c|c|c|c|}
\hline & & & \multirow{2}{*}{$\begin{array}{l}\text { Duodenal } \\
\text { Ulcer }\end{array}$} & \multirow{2}{*}{$\begin{array}{l}\text { Gastric } \\
\text { Ulcer }\end{array}$} & \multirow{2}{*}{$\begin{array}{l}\text { Gastritis/ } \\
\text { Erosions }\end{array}$} & \multirow{2}{*}{$\begin{array}{l}\text { Hiatus } \\
\text { Hernia }\end{array}$} & \multicolumn{2}{|c|}{ Miscellaneous } & \multirow{2}{*}{$\begin{array}{c}\text { Source } \\
\text { Unknowr }\end{array}$} \\
\hline & & & & & & & Varices & Other & \\
\hline $\begin{array}{l}\text { Haemoglobin }<7 \cdot 2 \mathrm{~g} / 100 \mathrm{ml} \\
\text { Severe shock } \because \cdots \\
\text { Blood transfusion units } \\
\text { Recurrent bleeding } \\
\text { Mortality }\end{array}$ & $\begin{array}{l}\ldots \\
\ldots \\
\ldots \\
\ldots \\
\text { ther } \\
\text { r ha }\end{array}$ & 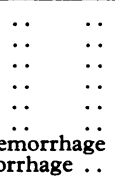 & $\begin{array}{r}19 \\
12 \\
35 \\
17 \\
25 \\
7 \\
3 \\
18\end{array}$ & $\begin{array}{r}54 \\
15 \\
49 \\
26 \\
44 \\
17 \\
5 \\
30\end{array}$ & $\begin{array}{l}31 \\
16 \\
25 \\
14 \\
29 \\
13 \\
5 \\
31\end{array}$ & $\begin{array}{r}18 \\
5 \\
20 \\
9 \\
15 \\
3 \\
2 \\
10\end{array}$ & $\begin{array}{l}32 \\
16 \\
56 \\
40 \\
56 \\
28\end{array}$ & $\begin{array}{r}30 \\
9 \\
34 \\
17 \\
28 \\
38\end{array}$ & $\begin{array}{r}17 \\
3 \\
19 \\
2 \\
12 \\
15 \\
8 \\
60\end{array}$ \\
\hline
\end{tabular}

TABLE X-Ages of Patients with Haematemesis or Melaena or Both admitted to Hospital in the Two Aberdeen Surveys. Figures are Percentages

\begin{tabular}{c|c|c}
\hline Age in Years & $1941-8^{*}$ & 1967 and 1968 \\
\hline$<40$ & $20 \cdot 8$ & $17 \cdot 2$ \\
$40-59$ & $50 \cdot 0$ & $34 \cdot 0$ \\
$60-69$ & $17 \cdot 4$ & $22 \cdot 2$ \\
$\geqslant 70$ & $11 \cdot 7$ & $26 \cdot 6$ \\
\hline
\end{tabular}

${ }^{*}$ Needham and McConachie (1950).

in 583 haematemesis was the presenting feature and in 407 $(70 \%)$ no further bleeding occurred in hospital. There were 234 episodes of melaena without haematemesis, and of these cases $181(77 \%)$ did not bleed again. The mortality in the 588 patients not bleeding again was $7.8 \%$, which is in marked contrast to the $28.8 \%$ (table IX) among those who continued to bleed or bled again in hospital (Jones et al., 1973). About onequarter of all the patients suffered severe haemorrhage as shown by a fall in haemoglobin level to below $7 \cdot 2 \mathrm{~g} / 100 \mathrm{ml}$, or they showed signs of moderate to severe hypovolaemic shock. Not all these severe haemorrhages occurred in those who continued to bleed or bled again in hospital. In the duodenal ulcer group 25 patients required transfusion of 7 or more units of blood and 16 were admitted with a haemoglobin of less than $7 \cdot 2 \mathrm{~g} / 100$ $\mathrm{ml}$ but did not bleed again. Among the gastric ulcer cases there were three such patients, two among patients with gastritis and one in the hiatus hernia group.

Mortality.-Deaths in the group who did not bleed again after admission reflect for the most part their advanced age and serious coincidental disease. In the 306 patients in the peptic ulcer group there were 12 deaths. Eight patients with an average of 72 years died from bronchopneumonia or heart disease. Among the four treated surgically two died from postoperative coronary thromboses and two from pulmonary embolism. Of the 53 patients in the miscellaneous group who died 31 did so from the malignant disease, which was the cause of their bleeding and which was mostly at an advanced stage.
Eleven died from cardiovascular disease. Six of the 21 incidents of variceal bleeding ended fatally, four in liver failure. There were two deaths in the elderly after resection for diverticulitis, one death from a perforated oesophageal stricture, one from pulmonary embolism, and one from severe acute pancreatitis with alimentary haemorrhage. Very few of these deaths among patients who did not have further haemorrhage could therefore be considered to be preventable. Only three of the 53 patients who died were under 60 years of age; one had varices, one inoperable carcinoma of the colon, and one inoperable gastric carcinoma.

Surgical Treatment.-This can best be examined in the peptic ulcer group of 511 patients. Seventy-five operations were performed to stop bleeding, with 18 deaths (Jones et al., 1973). Another 75 elective operations were performed before discharge to prevent further symptoms or complications; five patients died, three from coronary thrombosis and two from pulmonary embolism. Both the latter patients had waited eight to 10 days after admission before semi-elective surgery was carried out. Nearly all the gastric and colonic carcinomas proved to be large and advanced and many had metastasized, but benign gastric and colonic neoplasms were resected. No emergency resections were needed for diverticular bleeding. Five patients with varices required urgent surgery; Linton's operations were performed in three, of whom two died in liver failure, and two patients who had urgent portacaval shunts survived.

\section{Discussion}

The few reports which relate the incidence of acute alimentary tract haemorrhage to the population at risk show a remarkable variation in the demand for hospital beds. In Oxford Schiller et al. (1970) reported a yearly admission rate of 47 per 100,000 population, which is half of the rate found in Aberdeen ( 92 per $100,000)$ and one-third of that found in a semirural population in southern Sweden (144 per 100,000; Herner et al., 1965). 
The data reported here are believed to give an accurate picture of alimentary tract haemorrhage in the adult population of northeast Scotland because $(a)$ all the data were collected during the time that the patient was in hospital, and $(b)$ virtually all patients in the region who require hospital admission for serious illness come to Aberdeen.

If the miscellaneous group is extracted from this series some interesting comparisons can be drawn with the previous survey of peptic ulcer haemorrhage conducted in this region for the years 1941-8 (Needham and McConachie, 1950). There was a notable increase in the proportion of elderly people being admitted to hospital (table X). There was also a steep rise from a war-time admission rate of 13.3 per 100,000 to 76 per 100,000 some 20 years later. If these figures apply to the United Kingdom as a whole then haematemesis and melaena account each year for 47,000 hospital admissions, and they make up more than $8 \%$ of all emergency admissions to medical wards. Many of these patients require prolonged intensive medical and nursing care and some will make major demands on the judgement and technical skill of surgeons. They account for some 6,000 deaths each year-a figure which gains perspective when compared with the 7,880 deaths from road accidents which occurred in the United Kingdom during 1967 (Registrar General, 1968; Registrar General, 1969).

The collection of data at the time of bleeding allowed the recognition of those patients who were already in hospital when they bled. This group increased the total numbers by $10 \%$ and the mortality from $10 \%$ to $13.7 \%$. Thirty-seven of these 74 patients already in hospital suffered continued or true recurrent bleeding, with a mortality of $51 \%$. Among the other 37 the mortality of $38 \%$ was greatly in excess of the mortality $(5.6 \%)$ experienced by all other patients who did not suffer continued or recurrent bleeding. The sources of bleeding in these 74 patients showed the same pattern as in other patients. It appears that their advanced average age and the uniform presence of other major complicating disease accounted for their very high mortality rate. A similar finding was made by Hamilton et al. (1965).

Gardiner et al. (1966) and Hall et al. (1972) found a peak incidence of bleeding in January, with a summer fall-off, but the present findings agree with the conclusions of Schiller et al. (1970) in that this tendency, though present, is slight.

The finding of a significant excess of patients in social class II and also in the socioeconomic groups containing foremen and skilled workers seems to indicate an undue incidence among those who carry an intermediate grade of responsibility. Doll et al. (1951), in a detailed examination of occupational factors in major dyspepsia, particularly mentioned foremen as being prone to peptic ulcer, though they found no relation between peptic ulcer and social class. In contrast Pulvertaft (1959) found that the incidence of both gastric ulcer and duodenal ulcer progressively increased in passing from social class I to social class V. The three series are not easily compared but it seems that those who sustain occupational pressures both from above and from below are especially liable to duodenal ulcers which bleed. There is also a suggestion in the present series that this may be true for those under strain in personal affairs.

It is not surprising that close attention is traditionally paid to the previous dyspeptic and radiological history of a patient who is bleeding because it should be a guide to the source of the present haemorrhage. The results of this survey show just how unreliable this information can be (tables IV and V). The most dangerous haemorrhages occur among those who have no dyspeptic history, and this agrees with the findings of Coghill and Willcox (1960) and Hamilton et al. (1965). The previous bariummeal result is for the individual patient an unreliable guide to the source of the current bleed, especially for peptic ulcers. This coincides with the observation of Palmer (1969), who found that among patients in whom a previous diagnosis of duodenal ulcer had been made $38 \%$ were not bleeding from the duodenum.
Likewise Cammock et al. (1963) noted that the finally proved source of bletding was often not the lesion that the patient was known to have at the time of admission. It is surprising to see the relatively large proportion of patients with a history of previous bleeding. This proportion was present in all diagnostic groups and not only those with peptic ulcers (table IV). It is also curious that contrary to expectation a history of previous haemorrhage is associated with a better prognosis-a point made by Coghill and Willcox (1960), Hamilton et al. (1965), and McEwan et al. (1969).

There was no proof of the source of bleeding in most of the 63 patients (66 episodes) in the hiatus hernia group. Nevertheless, careful follow-up three years later showed only two patients in whom subsequent events suggested that there may have been another explanation-one developed carcinomatosis from a neoplasm of the kidney and one possibly had a gastric carcinoma.

Particular efforts were made to determine whether drugs had played a part in initiating bleeding. The definite effect of aspirin, the lack of effect of alcohol alone, and the remarkable synergistic effect of alcohol plus aspirin in promoting bleeding have already been reported (Needham et al., 1971). Most of the patients who bled while on anticoagulant therapy were somewhat out of control but constituted only a small proportion $(1.4 \%$ a year) of all those on long-term therapy at that time. The 10 patients on steroids must represent only a tiny proportion of all those taking these drugs in the region. We found no evidence to suggest undue alcoholism in our patients. It is interesting that oesophageal varices make up $3 \%$ of the present series, which is similar to the proportion of $2.4 \%$ reported in Oxford (Schiller et al., 1970) and $2.7 \%$ (Jones, 1969) and $2.9 \%$ (Cocks et al., 1972) found in London.

Further haemorrhage after admission whether in the form of continuing bleeding or true recurrence affected more than a quarter of the patients; its grave effect on mortality is shown in table IX and has been discussed in detail by Jones et al. (1973).

Virtually all emergency surgical treatment was performed on patients with further haemorrhage. Seventy-five patients with chronic peptic ulcers had a semi-elective operation performed about a week after admission for haemorrhage. This is a common practice designed to save time and prevent future trouble but it carries an undue risk of pulmonary embolism. Two patients who had a vagotomy and gastroenterostomy and one who had a benign leiomyoma of the stomach excised eight to 10 days after admission died from pulmonary embolism postoperatively. These semi-elective operations should carry the negligible mortality now associated with planned gastric surgery. Therefore it seems advisable to tell these patients that surgery is indicated, to discharge them for three to four weeks with instructions to be ambulant and active, and then to readmit them direct to the surgical ward.

The problem of haematemesis and melaena still constitutes a major challenge. These conditions are common, their causation is diverse, and the precipitating factors are capricious. Determination of the source can be difficult though this aspect of care is being greatly facilitated by the use of fibreoptic endoscopy. For the patients who do not bleed again after admission to hospital the outcome is largely determined by the presence or absence of other major disease; for those who do bleed after admission the outlook is always serious.

Schiller et al. (1970) found the overall prognosis little changed over the three quinquennia between 1953 and 1967. The present survey confirms that prognosis has not shown the improvement that might have been hoped for and expected with recent advances in medical and surgical care.

We thank all our medical and surgical colleagues who gave us free access to the patients under their care. Grateful acknowledgement is rendered to the North-Eastern Regional Hospital Board (Scotland), who financed the survey. We are indebted to our secretaries Mrs. C. Smith and Mrs. J. Amonoo for much help at all stages of the work. 


\section{References}

Allan, T. M. (1971). Personal communication.

Cammock, E. E., Hallett, W. Y., Nyhus, L. M., and Harkins, H. N. (1963). Archives of Surgery, 86, 608

Cocks, J. R., Desmond, A. M., Swynnerton, B. F., and Tanner, N. C. (1972). Gut, 13, 331 .

Coghill, N. F., and Willcox, R. G. (1960). Quarterly fournal of Medicine, 29, N.S., p. 575.

Doll, R., Jones, F. A., and Buckatzsch, M. (1951). Medical Research Council Special Report Series, No. 276. London, H.M.S.O.

Gardiner, G. C., Pinsky, W., and Myerson, R M. (1966). American fournal of Gastroenterology, 45, 22.

General Register Office, Scotland (1956). Census, 1951, vol. 4. Edinburgh, H.M.S.O. General Register Office, Scotland (1964). Census, 1961, vol. 1. Edinburgh,
H.M.S.O.

General Register Office, Scotland (1967). Sample Census, 1956. Edinburgh, H.M.S.O.

Hall, W. H., Read, R. C., Mesard, L., Lee, L. E., and Robinette, C. D. (1972). Gastroenterology, 62, 1120.
Hamilton, J. E., Harbrecht, P. J., Robbins, R. E., and Noland, J. L. (1965). Surgery, Gynecology and Obstetrics, 121, 545.

Herner, B., Kalgard, B., and Lauritzen, G. (1965). Acta Medica Scandinavica, 177, 483.

Jones, F. A. (1969). British Medical fournal, 2, 267.

Jones, P. F., Johnston, Shirley J., McEwan, A., Kyle, J., and Needham, C. D. (1973). British Medical fournal, 3, 660. Ewan, A., Johnston, Shirley

Needham, C. D., and McConachie, J. A. (1950). British Medical fournal, 2, 133.

Needham, C. D., Kyle, J., Jones, P. F., Johnston, S. J. and Kerridge, D. F. (1971). Gut, 12, 819.

Palmer, E. D. (1969). Fournal of the American Medical Association, 207, 1477. Pulvertaft, C. N. (1959). British Fournal of Preventive and Social Medicine, 13,131 . Registrar General for Scotland (1968). Annual Report for 1967. Edinburgh,
H.M.S.O.

Registrar General (1969). Statistical Review of England and Wales for 1967. London, H.M.S.O.

Schiller, K. F. R., Truelove, S. C., and Williams, D. G. (1970). British Medical fournal, $2,7$.

\title{
Further Haemorrhage after Admission to Hospital for Gastrointestinal Haemorrhage
}

\author{
PETER F. JONES, SHIRLEY J. JOHNSTON, ARTHUR B. MCEWAN, JAMES KYLE, \\ CHARLES D. NEEDHAM
}

British Medical fournal, 1973, 3, 660-664

\section{Summary}

During 1967 and 1968817 episodes of acute alimentary tract haemorrhage were treated in Aberdeen hospitals. In 229 cases further haemorrhage occurred in hospital, with a mortality of $\mathbf{2 8 . 8} \%$; the mortality among patients who did not have this complication was $7 \cdot 8 \%$. This was true of any kind of further haemorrhage. As judged by transfusion requirements and mortality the severity of the further haemorrhage was unaffected by its occurrence as haematemesis and melaena or as melaena only or by whether it took place before or after 48 hours from the time of admission. The occurrence of further haemorrhage did not appear to be affected by the sex or blood group of patients, by aspirin ingestion, or by a history of a previous haemorrhage.

The effects of the occurrence of further haemorrhage, of the age being over 60 years, or of coincidental disease being present were of descending importance in regard to mortality.

Among 151 patients with peptic ulcer and further haemorrhage half required urgent surgery and $20 \%$ died. Further haemorrhage is a dangerous condition and its occurrence should immediately signal the need for vigilance and for urgent consultation between physician and surgeon. Any delay in treatment entails increased mortality.

Foresterhill and Associated Hospitals, Aberdeen

PETER F. JONES, M.CHIR., F.R.C.S., Consultant Surgeon

JAMES KYLE, M.CH., F.R.C.S., Consultant Surgeon

CHARLES D. NEEDHAM, M.D., F.R.C.P., Consultant Physician

Gastroenterological Unit, Aberdeen Royal Infirmary, Aberdeen AB9 2ZB

SHIRLEY J. JOHNSTON, F.R.C.S., Research Registrar

St. James's Hospital, Leeds LS9 7TF

ARTHUR B. McEWAN, F.R.C.S., Senior Surgical Registrar

\section{Introduction}

Patients admitted to hospital with acute alimentary tract haemorrhage can be divided into those who show evidence of further bleeding after admission and those who do not. All published reports have shown that bleeding after admission is of grave prognostic significance; mortality has been found to be multiplied by factors of 12 (Avery Jones, 1956), 10 (Needham and McConachie, 1950), and six (Schiller et al., 1970) among patients with further bleeding in hospital. Further haemorrhage is easy to recognize when a patient repeatedly vomits blood. However, only two-thirds of the group do this; the remainder have melaena only or bleed internally. The objects of this paper are to examine the problems presented by further haemorrhage occurring in hospital and to study the behaviour and response to treatment of patients who suffer this complication.

The term further haemorrhage (F.H.) has been adopted because it can include both true recurrent bleeding and bleeding that has continued from the time of admission. Patients who were admitted to hospital having had haematemesis or melaena were considered to have suffered F.H. when (1) in spite of adequate resuscitation the patient continued to show signs of blood loss requiring further transfusion, with (or occasionally without) further haematemesis or melaena, or (2) after an interval during which the patient showed no signs of internal bleeding there was $(a)$ vomiting or nasogastric aspiration of freshly-shed blood or $(b)$ renewed evidence of hypovolaemic shock or rapidly progressive anaemia.

Melaena alone was not accepted as evidence of F.H. because it is not possible to distinguish blood shed before admission from that due to more recent haemorrhage.

\section{Method}

All patients over 12 years of age in the Aberdeen hospitals during 1967 and 1968 who had haematemesis or melaena were interviewed and detailed contemporary records were made. A total of 795 patients suffered 817 episodes of bleeding (Johnston et al., 1973). Altogether 192 patients suffered F.H. after being admitted for either haematemesis or melaena or both. Among 74 patients who were already in hospital for other reasons when they first showed alimentary bleeding there were 37 who had 